\title{
Fentanyl Buccal Soluble Film
}

National Cancer Institute

\section{Source}

National Cancer Institute. Fentanyl Buccal Soluble Film. NCI Thesaurus. Code C78461.

A transmucosal formulation consisting of a small, mucoadhesive, bioerodible polymer disc formulated with the citrate salt of fentanyl, a synthetic anilidopiperidine opioid with analgesic activity. Upon application, fentanyl buccal soluble film rapidly releases fentanyl which is quickly absorbed into the systemic circulation. Fentanyl selectively binds to and activates mu-opioid receptors in the central nervous system (CNS), thereby mimicking the effects of endogenous opiates. 